In the crania of the Primates, the jugal arch is composed of two bones, the zygomatic process of the squamosal, and the malar; which last, resting upon and articulating with the maxilla, is joined with the squamosal process by a serrated suture which inclines downwards and backwards, the amount of the inclination being modified in the various groups of this order. The strength and curvature of the arch also widely vary, as also does the extent to which the various crests and ridges for muscular attachment are developed. In man, the arch is generally slender, slightly curved in its horizontal axis, and presents a very moderate convexity upwards in its vertical currature. Owing to the very slight horizontal curvature outwards, the temporal fossa is relatively shallow, consequently allowing but little development of the temporal muscle This condition, howerer, is subject to modifications in the various races of man. The maximum breadth of the cranium is at the jugal arches, and it is at these points that craniologists now take the bi zygomatic diameter of the face.

Humphrey, in his "Human Skeleton," in speaking of this arch. says : "The upper surface of its root forms a smooth channel for play of the temporal muscle. In the negro the greater width of this channel throws out the zygoma into stronger relief, and, added to the fiatness of the squamosal portion, affords more space for the temporal muscle." In other words, the negro has a more fully deveioped temporal muscle than the white man; that is, he approaches nearer to the Carnivora. This general statement is not confirmed by any cranial measurements, neither does Mr. Humphrey state what he means by a negro - of course, one of the black race. But under the term " black race" are included the Oceanic negroes, as well as the natives of central and southern Africa Probably he intended, as in common parlance, to designate the African, although this designation is ambiguous, as it is well known that the crania of the different tribes of Africa differ very essentially in their general formation, as well as in their special cranial measurements.

Although the cephalic measurements of Broca, Topinard, and others allow a slight increase in the horizontal curvature of the arch in certain instances, which, if they indicate anything, signify a greater development of the temporal muscle, as well as a more extended surface for the attachment of the masseter, both of which, as we have seen, highly characterize the arch in the Car. nivora ; yet, as Topinard remarks, in speaking of the bi-zygomatic diameter, which may be accepted as the criterion of the greatest facial width: "This measurement by itself of ten presents difficulties, purely accidental and local, and entirely apart from the general type. Thus, in every race, cases occur in which the zygomatic process of the squamosal, insteal of joining directly with the molar, bends outwards and then resumes the general characteristic direction of the arch, whether this be straight or gently curved. The greatest width under these circumstances falls upon the summit of the bend, which causes the measurement to be unduly augmented."

As a result of the measurements taken upon the crania of the Africans in the collection of the Peabody Museum, and of the Harvard Medical School, there was a slight increase in the bizygomatic breadth over those of other mixed European skulls. But no dependence should be put in such measurements, for although in one collection the crania were classified in gencral as African, nothing was known of their history, and still less of those with which they were compared.

According to an extract from M. Pruner-Bey's tables, as given by Topinard, the bi-zygomatic breadth, compared with the total length of the face, is greater in the Esquimo, Chinese, Scandinavians, Germans (south), and New Caledonians than it is in the negroes of $\Lambda$ frica. In the eategory of crania in the British Museum Mr. Flower gives the index of breadth of the African negroes of various tribes. The low conformation of those, in this respect, is only exceeded by the Eskimo, Australians, Melanesians, Kaffirs, and Zulus.

In order to substantiate the statement made by Mr. Humphrey it would seem to be much the most scientific method to ascertain by measurement the actual width of the groove in the upper surface of the posterior root of the zygoma of the African skull, and compare this with that of other races. This can be properly ef- fected by taking first the bi zygomatic breadth. and then the bisquamosal at the most prominent point on the line of suture between the squamosal and alisphenoid, the difference between the two measurements would give the breadth of groove.

Cuvier reminds us that the size of the temporal fossa and its muscle have close relation with the age of the animal. In the young, the brain and its case are developed, but the jaws are small, and the forces which move them are wanting in energy. But with age these last are developed, while the intellectual powers constantly diminish. In civilized man the equilibrium is maintained between the growth of the brain-case, the intellectual powers, and the masticatory organs. Can any relation, however remote, be traced between the developed masticatory powers of the uncivilized negro, and the flattened squamosal in his braincase as described by Mr. Humphrey?

D. D. Slade.

Cambridge, Mass., May 27.

\section{Anatomy of the Apteryx.}

By far one of the most important anatomical papers which has appeared since the present year commenced is a memoir by Professor T. Jeffrey Parker, F.R.S., of the University of Otago, New Zealand, entitled "Observations on the Anatomy and Development of Apteryx." This remarkable bird-form, now becoming quite rare, is so well known to biologists that the several species of the genus will require no special description from me here. Nor will the vast importance to anatomical science of a complete study of its structure and embryology stand in need of comment. What Mr. Parker has accomplished in that direction is now before me, - one of the classical publications of the Royal Society of London, brought out through its Philophical Transactions, it being the work to which I desire to invite attention.

This monograph is in the usual quarto form, and covers 134 pages, and is illustrated by sixteen lithographic plates, beautifully executed in color. These last are devoted to the external characters of the embryo; to sections of the same; to graphic representations of the rate of growth; to the morphology of the skull and skeleton of the young at various stages; and to certain parts of the anatomy of the adult. They include 310 figures. Aptery $x$ bulleri, A. australis, and A. oueni are followed, more or less completely, through fourteen various stages of their growth, the whole resulting in a very full embryological chapter. Among the more important points arrived at by our author are, (1) in the adult Apteryx, as well as in advanced embryos, the pterylosis is by no means uninterrupted, as was originally supposed to be the case by Nitsch; (2) that the lateral apterial space has a definite function in connection with the attitude assumed by the bird during sleep; (3) that the study of the structure of the wing of Apteryx lends support to the view that the Ratitce are the descendants of birds which possessed the power of flight; (4) the demonstration of the law of growth of Apteryx, giving the stages in which the head, beak, brain, sternum, and limbs arrive at their maximum dimensions, and the comparative and relative rates of the growth; (5) the specific and sexual differences; (6) the discovery of nine more muscles in the wing of the adult than were known to Owen, our former authority on the subject; and (7) the presence of the pecten in the eye during embryonic life.

In conclusion the phylogeny is given, and under that caption are arrayed the characters which go to support the view that Apteryx is derived from a typical avian form capable of flight. Fifteen characters are well chosen for that purpose, - the only opposed one suggested being the total absence of rectrices in $A p$ teryx. This résumé is followed by a summary of other sets of charaeters supporting (1) the derivation from a more generalized type than existing birds. and the converse, (2) as exhibiting greater specialization than other birds. Fifty-five works are given in a list at the close of the monograph, as having been referred to during its production. Only one American authority is mentioned, and we must believe that the important labors of Morse on "The Carpus and Tarsus of Birds" would have been found useful, to say not a word of a number of others.

It remains for me but to say that this admirable paper of Professor Parker's will surely make its influence felt at once, and will 
receive a hearty welcome from anatomists in all quarters of the globe, as a most thorough and capable contribution to the subject of rertebrate morphology.

R. W. SHUFELdT.

Takoma, D.C., May 29.

\section{BOOK-REVIEWS.}

The Defences of Norumbega. By EBEn Norton Horsford. Boston and New York, Houghton, Mifflin, \& Co., 1891.

In this sumptuouslv published volume, with its numerous reproductions of old maps, its photographic views and engravings, Professor Horsford returns to the arena in defence of his favorite theory that in the eleventh century the Northmen established an important walled city on the site where Watertown, Mass., now stands. He believes that he has discorered its stone-built walls, its ancient stone-paved streets, and the remains of its docks and wharves. Other local antiquaries see in these remains merely the vestiges of some dams, drains, and stone fences of the early New England farmers, and it appears that Professor Horsford bas not succeeded in persuading any of the resident investigators of the interpretation he has so much at heart. Furthermore, the most recent and careful study of the Sagas of the Northmen's voyages to America - that by Professor Gustav Storm - declares that the records do not admit of placing the southern limit of their explorations south of Nova Scotia. We must therefore return the Scotch verdict of "not proven," on the evidence before us.

Civilization: an Historical Review of its Elements. By CharLes MORRIs. Chicago, S. C. Grigg's \& Co. 2 vols.

Mr. MORRIS is known as a fertile writer on topics relating to evolution, and as the author of "The Aryan Race" and some other works. In the volumes before us he undertakes " to set forth the philosophy of human progress and indicate the evolutionary steps by which the world of man has passed upward from primitive savagery to modern enlightment."

In carrying out this plan he selects such subjects as government, war, religion, law, commerce, literature, and the arts, and portrays their growth from a primitive form to that condition in which we find them to-day. This is usually accomplished in a comprehensive and satisfactory manner; but the reader is not unfrequently at a loss, as he is repeatedly in Mr. Morris's " Aryan Race," to distinguish between fanciful hypotheses of the writer and definite results of other investigators, for his pages offer no references as guides, and his assertions usually go unsupported. As a popular work, however, it deserves commendation.

\section{AMONG THE PUBLISHERS.}

The first number of Pantobiblion has just been received from the American publishers, Messrs D. Appleton \& Co., New York. This new periodical has its main office in St. Petersburg, and is edited by A. Kersha, a civil engineer. The title-page of the number received is in English, but the text is printed in fifteen different languages. The purpose of Pantobiblion is to help those concerned with the applied sciences generally in securing information of the current scientific literature in their specialities. To do this the journal contains a classified list of all new books in all the principal languages, a series of reviews of the leading scientific publications, and a summary of the contents of current periodical literature. It is intended to add to these, critical notices of the principal articles in scientific periodicals, and a miscellaneous departnent to be devoted to short notes on current scientific literature. This first number contains 1.200 titles of new publications, 80 reviews, and the "contents" of 270 periodicals. That it may not be thought that this new venture is only for those interested in applied science, it should be mentioned that the subjects included cover a wide range in the physical sciences as well as in engineering, and that botany and geology receive some attention. There has been some delay in getting out this initial number, - a delay which is by no meaus surprising considering the enormous labor involved in the editing and manufacture of a periodical containing such a mass of disconnected information, - but the following numbers are promised to follow in rapid succession. Whether Pantobiblion is to be a financial success or not is more than we can say; but certainly every one interested should take the first opportunity for examining a copy, to see whether it meets his needs. There is such an enormous amount of matter between the covers that the first impression on us is somewhat appalling.

-The University Extension movement takes so prominent a place among the educational influences of the age, says Nature, that a good account of the system has for some time been needed. This is supplied in " Eighteen Years of University Extension," by R. D. Roberts (Cambridge, University Press). Mr. Roberts, first as lecturer, then since 1881 as assistant and organizing secretary to the Cambridge Syndicate, and since 1886 as secretary to the London Society, has had the best possible opportunities of studying the new method, and of forming a judgment as to its fitness for the uses to which it is applied. He begins with an account of the origin and growth of the movement, then describes the character of the audiences, the reception of the idea by artisans, and the signs of earnestness displayed by various classes of students. Mr. Roberts also discusses the conditions of success, has a chapter on the consolidation of the work, and presents a summary of results. No essential fact has been omitted, and the general impression which will be left on the minds of most readers probably is that those connected with the movement have done much to foster and to satisfy the desire of a very large number of persons for intellectual training. There are certain rules-some of them rather difficult-with which the system must ve brought into accord if it is to be capable of further development; and these are stated with much force and precision in the useful little volume.

- With the June number the Educational Review begins its second volume. At this season, when many young wen are considering where they will study in Europe, the article on "The Present Condition of the German Universities," by Professor Mattoon M. Curtis, has a timely interest. Other contributions to the number are: "Applications of Psychology in Education," by Dr. Mary Putnam Jacobi, illustrated with twenty-one diagrams; " The American High School," by Ray Greene Huling, president of the American Institute of Instruction; and "The Education of the Will," by Professor J. Clark Murray; a discussion between Mr. Albert L. Arey and Professor Fernando Sanford on "The Use of Text-books in Teaching Elementary Science," and one by Superintendent W. H. Maxwell on "Teachers' Salaries." The reviews are by Professors Jastrow of the University of Wisconsin, Waggener of the University of Texas, Venable of the University of Virginia, Genung of Amberst, Chapin of Wollesley, Myers of the University of Cincinnati, etc. The department of "Education in Foreign Periodicals" includes "Some Characteristics of a Sound Mind," "The School of the Future," and "The School for Oriental Languages at Berlin."

- The "Annual Report" of the Director of the Royal Alfred Observatory, Mauritius, for the year 1889 , as quoted in a recent number of Nature, shows that the island bas again enjoyed immunity from storms. The greatest hourly velscity of the wind was 31 miles. The almost total absence of tropical cyclones in the south Indian Ocean during the year is considered by Dr. Meldrum as another confirmation of the law that these cyclones are fewest in number and least intense in the years of least solar activity. The mean temperature was $0.7^{\circ}$ below the average for the last fifteen years, and below the average in every month except July and October. The maximum shade temperature was $93.1^{\circ}$ on March 27, and the minimum 52.4 $4^{\circ}$ on June 18. The rainfall was 8.56 inches above the average; the greatest fall in one day was 3.88 inches on March 11, although this amount was much exceeded in other parts of the island. On Jan. 1, a waterspout burst on the Pouce Mountain; Port Louis was flooded, and some persons were drowned. The collection of observations made at sea is actively carried on; $324 \mathrm{log}$-books were received, and the observations duly tabulated. The report also' contains observations made at the Seychelles and Rodriguez.

- Silver, Burdett, \& Co., Boston, announce "An Elementary Handbook of Potable Water," by Floyd Davis, professor of chemistry in Drake University. Chapter I. of the volume treats of pure water, and defines the terms pure and impure, wholesome and unwholesome, from the sanitary standpoint. Chapter II. is devoted to inorganic: constituents; Chapter III., to vegetable con- 